\title{
Effects of chronic treatment with 2,5-hexanedione on several behavioral measures in rats
}

\author{
M. E. PEREIRA and C. I. HUANG \\ Universidade Federal de Santa Maria, Santa Maria, Brazil \\ and \\ I. IZQUIERDO \\ Universidade Federal do Rio Grande do Sul, Porto Alegre, Brazil
}

\begin{abstract}
Exposure to hexacarbon compounds may cause several neurotoxic effects in both animals and humans. In the present study, we subcutaneously administered, chronically for 15-50 days, 2,5-HD (a toxic metabolic of $n$-hexane) to investigate its effects on open-field behavior, step-down inhibi-

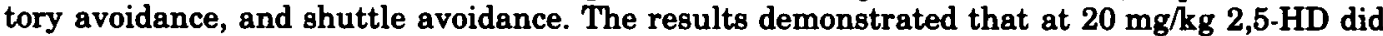
not alter any of the behavioral tasks analyzed. On the other hand, at $200 \mathrm{mg} / \mathrm{kg} 2,5$-HD caused significant reductions on body-weight gain (10\% at 25 days of treatment and $25 \%$ at 61 days) and the general motor activity of rats treated for 15 or 30 days; treatment did not interfere with habituation to the open field. Inhibitory avoidance performance was not affected, but shuttle avoidance was significantly impaired in the high-dose, long- and short-term treated rats, probably as a consequence of the general debilitation of motor activity in treated rats.
\end{abstract}

Exposure to hexacarbon compounds may cause distal axonopathy in the central and peripheral nervous systems of both humans and animals (Spencer, Schaumburg, Sabri, \& Veronesi, 1980). Various studies have demonstrated that workers occupationally exposed to n-hexane present peripheral polyneuropathy (Couri \& Milks, 1982; Herskowitz, Ishii, \& Schaumburg, 1971). n-Hexane is metabolized to a series of metabolites, including 1hexanol, 2-hexanol, 3-hexanol, 2-hexanone, 5-hydroxy2-hexanone, and 2,5-hexanedione (Couri \& Milks, 1982; DiVicenzo, Kaplan, \& Dedinas, 1976). Although the exact mechanism underlying the neurotoxic effects of hexacarbon compounds is not yet established, it has been demonstrated that the hexacarbon compound 2,5-hexanedione may cause severe toxic effects with chronic administration to animals, including severe deficits in motor and sensory performance (Abou-Donia, Makkawy, \& Campbell, 1985; Bastone, Frontali, Mallozzi, Sbraccia, \& Settini, 1987; DiVicenzo et al., 1976; Fedtke \& Bolt, 1987; Gerber \& O'Shaughnessy, 1986; Herskowitz et al., 1971; Misumi, Nagano, Kaisaku, \& Hitoshi, 1985). Furthermore, it has been suggested that 2,5-hexanedione is the main toxic metabolic compound derived from n-hexane in mammals. Recently, Ladefoged, Hass, and Simonsen, (1989) demonstrated that 2,5-hexanedione causes a reduction in balance time in the rotarod test when administered to rats in their drinking water. All these data suggest that

The authors are associated with the departments of biochemistry at their respective institutions. Correspondence should be addressed to M. E. Pereira, Setor de Bioquímica, CCNE-UFSM, Campus Universitario-Camobi, 97119-Santa Maria RS Brasil. 2,5-hexanedione causes motor disturbances in chronically exposed animals. However, research is lacking regarding the effects of chronic exposure to 2,5-hexanedione on other behavioral tasks. In the present work, we examined the effects of chronic treatment with 2,5-hexanedione at various doses and durations on the performance of adult rats in various behavioral paradigms.

\section{GENERAL METHODS}

\section{Drugs}

2,5-hexanedione (2,5-HD; acetonylacetone, 97\%) was obtained from Aldrich Chemical Co. (Milwaukee, WI). The drug was diluted in a vehicle consisting of $120 \mathrm{mM} \mathrm{NaCl}$ and $10 \mathrm{mM}$ phosphate buffer (pH 7.2). It was not possible to conduct a blind study since rats treated with both high and low doses of 2,5-HD present characteristic staining of the fur due to contact of the drug with the skin during injection. Furthermore, rats treated with $200 \mathrm{mg} / \mathrm{kg}$ of 2,5-HD show gross behavioral alterations that appear at about 25 days of treatment.

\section{Subjects}

Female Wistar rats (60-65 days old and weighing 140-170 g) were maintained in groups of 4 in opaque plastic cages. The rats had free access to water and food and were maintained on a 12-hlight/12-h-dark cycle. The drugs were administered between 0900 and $1300 \mathrm{~h}$ and 4 to $5 \mathrm{~h}$ before the rats were subjected to behavioral testing. For dose-adjustment purposes, the rats were weighed every 3 days.

Statistical analyses. In Experiments 1 and 2, behavioral data were analyzed by a 2 treatments (vehicle or 2,5-HD) $\times 2$ sessions (training and test) analysis of variance (ANOVA), with the sessions factor treated as a repeated measure. $F$ values for either main or interaction effects were presented in the text only when $p<.05$. In Experiment 2, body-weight data were included, and were analyzed by a two-way ANOVA ( 3 treatments $\times 6$ days), with the days factor treated as a repeated measure. 


\section{EXPERIMENT 1 \\ High-Dose Exposure}

\section{Procedure}

The rats were subcutaneously injected daily with the vehicle solution alone or with $200 \mathrm{mg} / \mathrm{kg}$ of 2,5-HD for 25 (short-term treatment) or 50 (long-term treatment) days.

To examine the behavioral effects of 2,5-HD treatment, the rats were subjected to two sessions of three different behavioral tasks: the first session was for training; the second was for testing. The interval between the two sessions was $24 \mathrm{~h}$. The rats were exposed to the behavioral tasks in the following fixed order: open field, stepdown inhibitory avoidance, and shuttle avoidance. The animals treated for $\mathbf{2 5}$ days (short-term treatment) were subjected to the behavioral tasks on Treatment Days 15 (open field), 20 (step-down inhibitory avoidance), and 25 (shuttle avoidance). The animals injected for $\mathbf{5 0}$ days (long-term treatment) were exposed to the tasks on Treatment Days 30 (open field), $\mathbf{4 0}$ (step-down inhibitory avoidance), and 50 (shuttle avoidance). The rats were tested at only one of the two exposure periods.

Open field. The number of rearing responses and the number of crossings were recorded for $5 \mathrm{~min}$ in an open-field arena with a floor that was divided into $1213-\mathrm{cm}$ squares (Pereira, Medina, \& Izquierdo, 1989).

Step-down inhibitory avoidance. The sessions were run in a $50 \times 25 \times 25 \mathrm{~cm}$ box with a grid floor. The left portion of the grid was covered by a platform $(7 \times 25 \times 5 \mathrm{~cm}$ high). In the training session, the rat was gently placed on the platform facing the rear left corner. The time the rat remained on the platform was recorded. When the rat stepped down with all four paws on the grid, a $0.2-\mathrm{mA}$ shock was applied to the grid until the animal climbed back onto the platform. Twenty-four hours after training, the rat was subjected to a test session. The rat was placed on the platform as on the previous day, and the latency for stepping down onto the grid was recorded. Step-down latency differences between test and training sessions were considered to be a measure of retention. A limit of $300 \mathrm{sec}$ was imposed on this measure.

Shuttle avoidance. The two sessions were run in a box similar to that used in the inhibitory avoidance task, except that the platform was removed and a strip of acrylic, $0.5 \mathrm{~cm}$ wide, was placed between the two central bars of the grid. The bars on each side of the strip were independently connected to an electric stimulator. Each rat was presented with 305 -sec tones (conditioned stimuli; CS), followed by 0.5-mA scrambled footshock (unconditioned stimuli; US) until the animal crossed the barrier to the opposite side of the box, unless the rat made a shuttle response to the tone, in which case the tone was interrupted and the shock scheduled for that trial was canceled. The number of shuttle responses and the number of intertrial responses were recorded automatically. An intertrial response was recorded when the animal crossed from one side of the box to the other during a period in which the CS or US was turned off. Twenty-four hours after training, the rats were subjected to an identical test session (Pereira, Dalmaz, Rosat, \& Izquierdo, 1988; Pereira, Rosat, Huang, Godoy, \& Izquierdo, 1989).

\section{Results}

The two-way ANOVA revealed a significant effect of $2,5-\mathrm{HD}(200 \mathrm{mg} / \mathrm{kg})$ on the number of rearing responses for rats treated for 15 days $[F(1,29)=17.49, p<.001]$ or 30 days $[F(1,23)=8.03, p<.01]$. The ANOVA also revealed significant effects of sessions for groups treated for 15 days $[F(1,29)=32.29, p<.001]$ or 30 days $[F(1,23)=40.91, p<.001]$. Post hoc comparisons on simple effects demonstrated that rats in all groups made a significantly lower number of rearing responses in the second session than they had in the first session (Table 1).

The ANOVA for crossing responses yielded results similar to those found for rearings. The drug caused a significant reduction in the number of crossings made by rats treated for 15 days $[F(1,29)=25.70, p<.001]$ or 30 days $[F(1,23)=35.15, p<.001]$. The ANOVA also revealed significant effects of sessions for rats treated for 15 days $[F(1,29)=8.69, p<.01]$ or 30 days $[F(1,23)=$ $29.16, p<.001]$. Post hoc comparisons on simple effects showed that rats in all groups made a significantly fewer number of crossings in the second session than they had in the first (Table 1).

The ANOVA for step-down inhibitory avoidance (Table 2) revealed a significant main effect of sessions for rats treated for 20 days $[F(1,29)=41.37, p<.001]$ and 40 days $[F(1,22)=39.47, p<.001]$. Post hoc comparisons on simple main effects showed that, for all groups, step-down latency was significantly greater in the test session than in the training session.

The ANOVA for shuttle-avoidance data (Table 3) revealed a significant main effect of the compound $(200 \mathrm{mg} / \mathrm{kg})$ on the number of shuttle responses for rats treated for 25 days $[F(1,27)=30.65, p<.001]$ and 50 days $[F(1,35)=22.31, p<.001]$. The ANOVA re-

Table 1

Effect of Chronic Treatment With $2,5-\mathrm{HD}(200 \mathrm{mg} / \mathrm{kg})$ for 15 or 30 Days on Number of Rearings and Crossings in the Open Field

\begin{tabular}{|c|c|c|c|c|c|c|c|c|c|}
\hline \multirow{3}{*}{$\begin{array}{c}\text { Treatment } \\
\text { Days }\end{array}$} & \multirow[b]{3}{*}{ Treatment } & \multicolumn{4}{|c|}{ Rearings } & \multicolumn{4}{|c|}{ Crossings } \\
\hline & & \multicolumn{2}{|c|}{ Training } & \multicolumn{2}{|c|}{ Test } & \multicolumn{2}{|c|}{ Training } & \multicolumn{2}{|c|}{ Test } \\
\hline & & $M$ & $S E$ & $M$ & $S E$ & $M$ & $S E$ & $M$ & $S E$ \\
\hline \multirow{2}{*}{15} & Vehicle & 49.1 & 2.4 & 38.6 & 3.3 & 107.1 & 3.8 & 93.7 & 7.3 \\
\hline & 2,5-HD & 38.5 & $1.6^{*}$ & 23.4 & $3.2 \dagger$ & 79.5 & $3.9^{*}$ & 61.9 & $6.6 \ddagger$ \\
\hline \multirow{2}{*}{30} & Vehicle & 42.5 & 2.7 & 25.0 & 2.8 & 91.2 & 5.2 & 66.7 & 7.7 \\
\hline & 2,5-HD & 30.9 & $2.4 \dagger$ & 20.2 & 2.3 & 60.3 & $3.6^{*}$ & 43.8 & $4.7 \ddagger$ \\
\hline
\end{tabular}

Note-Values are expressed as means and standard errors for 12 to 16 rats per experimental group. As compared with same-session scores of vehicle-treated rats, ${ }^{*} p<.001, \dagger p<.002$, and $\ddagger p<.02$. $F$ tests for simple effects of sessions revealed significant reductions for all groups in both rearings and crossings in the test sessions vis-à-vis the training sessions. (Rearing responses-15 and 30 days, $p<.005$ for vehicle and 2,5-HD groups. Crossing responses-15 days, $p<.05$ for vehicle and 2,5-HD groups; 30 days, $p<.0005$ for vehicle group and $p<.01$ for 2,5-HD group.) 
Table 2

Effects of the Chronic Treatment With 2,5-Hexanedione $(200 \mathrm{mg} / \mathrm{kg})$ for 20 or 40 Days on Step-Down Latency (in Seconds) in the Inhibitory Avoidance Task

\begin{tabular}{|c|c|c|c|c|c|c|c|c|}
\hline \multirow[b]{4}{*}{ Treatment } & \multicolumn{8}{|c|}{ Treatment Day } \\
\hline & \multicolumn{4}{|c|}{20 Days } & \multicolumn{4}{|c|}{40 Days } \\
\hline & \multicolumn{2}{|c|}{ Training } & \multicolumn{2}{|c|}{ Test } & \multicolumn{2}{|c|}{ Training } & \multicolumn{2}{|c|}{ Test } \\
\hline & $M$ & $S E$ & $M$ & $S E$ & $M$ & $S E$ & $M$ & $S E$ \\
\hline Vehicle & 7.3 & 0.9 & 153.8 & 36.7 & 17.5 & 2.8 & 203.6 & 38.4 \\
\hline 2,5-HD & 11.0 & 1.0 & 189.2 & 34.5 & 39.8 & 8.9 & 202.2 & 43.9 \\
\hline
\end{tabular}

Note-Values are expressed as means and standard errors for 12 to 16 rats per experimental group. $F$ tests for simple effects of sessions revealed significant increases for all groups in step-down latencies in the test sessions vis-âd-vis the training sessions (20 days, $p<.001$ for vehicle and 2,5-HD groups; 40 days, $p<.0005$ for vehicle group and $p<.001$ for 2,5-HD group).

vealed a significant effect of sessions $[F(1,27)=4.66$, $p<.05$, for rats treated for 25 days; $F(1,35)=6.90$, $p<.02$, for rats treated for 50 days]. The treatment $\times$ sessions interaction was also significant for rats treated for 25 days $[F(1,27)=5.39, p<.03]$ but not for rats treated for 50 days. The interaction in rats treated for 25 days with 2,5-HD was due to the fact that while control rats significantly increased the number of shuttle responses made in the test session vis-à-vis those made in the training session, the rats treated with $200 \mathrm{mg} / \mathrm{kg}$ of $2,5-\mathrm{HD}$ did not increase the number of their avoidance responses.

With respect to intertrial responses, the ANOVA revealed a significant main effect of treatment $[F(1,27)=$ $10.35, p<.0001$, for rats injected for 25 days; $F(1,35)$ $=27.49, p<.001$, for rats treated for 50 days]; the effect of sessions and the interaction of treatment $\times$ session interaction were not significant. The effect of treatment was due to the fact that the 2,5-HD-treated rats made fewer intertrial crossings than did the vehicle group.

\section{EXPERIMENT 2}

Low-Dose Exposure

Since treatment with $200 \mathrm{mg} / \mathrm{kg}$ of 2,5-HD induced a marked effect on behavioral performance (except for step- down inhibitory avoidance), mainly on motor activity, we investigated the effect of chronic treatment with $20 \mathrm{mg} / \mathrm{kg}$ of 2,5-HD on the tasks used in Experiment 1. After longterm treatment (50 days), the animals were exposed to the tasks on Days 30 (open field), 40 (step-down inhibitory avoidance), and 50 (shuttle avoidance), as in the longterm treatment in Experiment 1.

\section{Results}

Since the body weights of vehicle-injected rats in Experiments 1 and 2 were similar, data from these vehicle groups were pooled and the two levels of 2,5-HD were included in the ANOVA. With respect to behavioral data, it was not possible to compare the two doses of 2,5-HD, because the vehicle-treated groups differed in their openfield behavior.

Figure 1 shows that treatment with $200 \mathrm{mg} / \mathrm{kg}$ of $2,5-$ HD significantly affected the body weights of the rats. The $20-\mathrm{mg} / \mathrm{kg}$ dose did not affect body weight. The ANOVA indicated significant main effects of treatment with 2,5-HD $[F(2,51)=12.23, p<.001]$ and of days $[F(5,255)=506.00, p<.001]$, and a significant interaction of treatment $\times$ days $[F(10,255)=36.01, p<$ $.0001]$. The interaction was significant because although rats treated with $200 \mathrm{mg} / \mathrm{kg}$ of 2,5-HD gained weight as a function of days, the increase was less than that observed in controls and that of the rats treated with $20 \mathrm{mg} / \mathrm{kg}$ of 2,5-HD.

The treatment with $20 \mathrm{mg} / \mathrm{kg}$ of 2,5-HD did not interfere with any of the behavioral tasks used in the present study. The results of the open-field test, step-down inhibitory avoidance, and shuttle avoidance of rats treated with $20 \mathrm{mg} / \mathrm{kg}$ of 2,5-HD are shown in Tables 4,5 , and 6 , respectively.

\section{DISCUSSION}

The objective of the present study was to examine the effects of chronic treatment with 2,5-hexanedione (2,5HD) on the performance of rats in three behavioral paradigms.

The higher dose of 2,5-HD significantly reduced the body weights of rats from Day 25 of treatment onwards.

Table 3

Effects of Chronic Treatment With 2,5-Hexonedione $(200 \mathrm{mg} / \mathrm{kg})$ for 25 or 50 Days on Number of Avoidance Responses and Intertrial Crossings in the Shuttle-Avoidance Task

\begin{tabular}{|c|c|c|c|c|c|c|c|c|c|}
\hline \multirow{3}{*}{$\begin{array}{c}\text { Treatment } \\
\text { Days }\end{array}$} & \multirow[b]{3}{*}{ Treatment } & \multicolumn{4}{|c|}{ Avoidance Responses } & \multicolumn{4}{|c|}{ Intertrial Responses } \\
\hline & & \multicolumn{2}{|c|}{ Training } & \multicolumn{2}{|c|}{ Test } & \multicolumn{2}{|c|}{ Training } & \multicolumn{2}{|c|}{ Test } \\
\hline & & $M$ & $S E$ & $M$ & $S E$ & $\boldsymbol{M}$ & $S E$ & $\boldsymbol{M}$ & $S E$ \\
\hline \multirow{2}{*}{25} & Vehicle & 9.3 & 0.9 & 12.9 & 1.6 & 6.7 & 1.2 & 6.9 & 1.5 \\
\hline & 2,5-HD & 4.3 & $0.7^{*}$ & 4.2 & $0.9 *$ & 3.4 & $0.8^{*}$ & 2.6 & 0.5 * \\
\hline \multirow{2}{*}{50} & Vehicle & 6.6 & 0.9 & 8.7 & 1.2 & 8.8 & 1.4 & 6.8 & 1.3 \\
\hline & 2,5-HD & 1.7 & $0.4^{*}$ & 3.2 & $0.8^{*}$ & 2.2 & $0.4 t$ & 1.3 & $0.3 \dagger$ \\
\hline
\end{tabular}

Note-Values are expressed as means and standard errors for 12 to 16 rats per experiment. As compared with the same-session scores of vehicle-treated rats, ${ }^{*} p<.01$, $\dagger p<.001$. $F$ tests for simple effects revealed that only the vehicle group showed a significant increase in the number of shuttle avoidances in the test session vis-à-vis the training session (25 days, $p<.05 ; 50$ days, $p<.01$ ). 


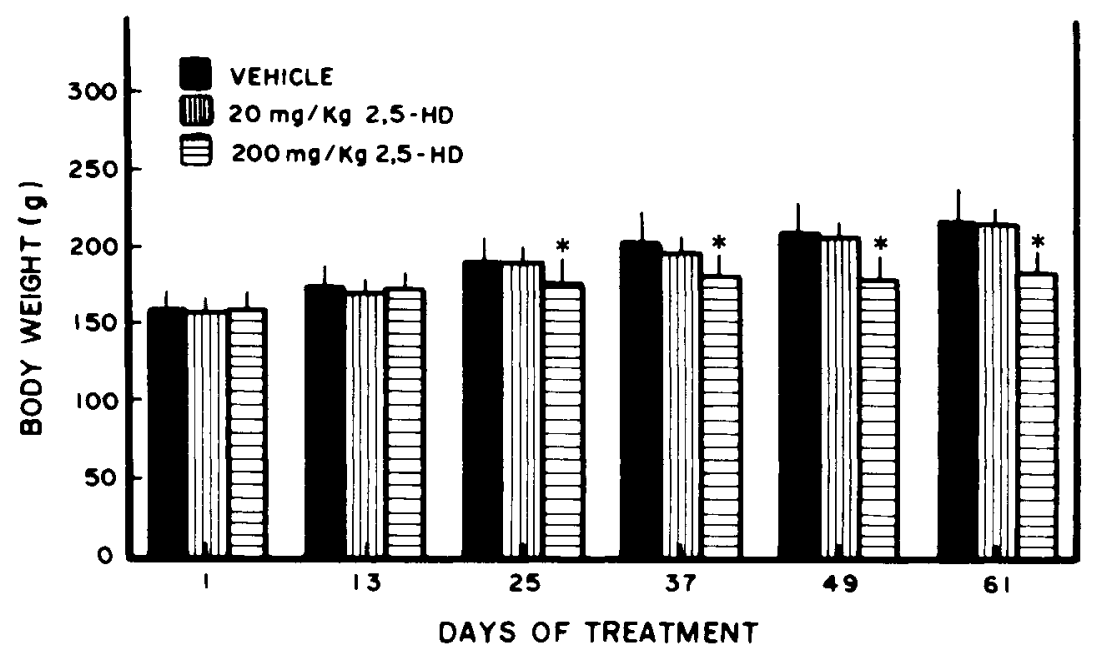

\begin{abstract}
Figure 1. Body weights of rats during 61 days of treatment with vehicle or 2,5-hexanedione (20 or $200 \mathrm{mg} / \mathrm{kg}$ ), s.c. Values are the means \pm standard deviations for 18 rats per group. $F$ tests for simple effects showed that all groups increased in body weight as function of days ( $p<.01$ for the vehicle and 20-mg/kg 2,5-HD groups; $p<.05$ for the 200-mg/kg 2,5-HD group). *Significant difference from the vehicle-treated rats at the $p<.05$ level by the Duncan multiple range test.
\end{abstract}

After 25 days of treatment, the HD-treated rats presented a body-weight deficit of about $10 \%$ as compared with controls; at the end of the treatment (61 days), the deficit was about $15 \%$. The effect observed in body weight in the present study is similar to that reported by Anthony, Boekelheide, and Graham (1983) but less accentuated than that observed by Bastone et al. (1987), Braendgaard and Sidenius (1986), DeCaprio and O'Neill (1985), and Rossi, Simonati, Rizzuto, and Toschi (1982).

The treatment with high doses of 2,5-HD caused a reduction in rearing and crossing responses at Treatment Days 15 and 30. However, these animals decreased the number of rearing and crossing responses in the test session vis-a-vis the training session, indicating that although motor performance was affected, the rats had habituated; so the memory of this task seems not to have been impaired by the treatment. Our results differ from those of Ladefoged et al. (1989) with regard to the onset of motor deficits. These authors detected motor deficits in rotarod performance after 3 weeks of treatment with 2,5HD in the drinking water. This difference may be ascribed to the method used to administer the compound. So this result suggests that 2,5-HD may affect motor activity before any effect on body weight is evident.

In contrast, the low-dose treated rats did not show any signs of motor disturbance. It is interesting to note that at 15 days of treatment, the rats showed no signs of gross motor disturbance and also no differences in body weight from that of controls, although they did show reduced open-field activity.

With $200 \mathrm{mg} / \mathrm{kg}$ of 2,5-HD, neurological signs, which could be observed by visual inspection, appeared at about 25 days of treatment. The rats presented slight paresis and a waddling gait. The intensity of these signs increased as the treatment proceeded. It is interesting to note that when the animals in the high-dose, short-term exposure groups were subjected to the inhibitory avoidance task, they began to exhibit gross behavioral signs of intoxication, and that they showed them clearly when subjected to shuttleavoidance training. The high-dose, long-term exposure rats showed signs of neurological intoxication at the time of training in all of the behavioral tasks.

Table 4

Effects of Chronic Treatment With 2,5-HD (20 mg/kg) for 30 Days on the Number of Rearings and Crossings in the Open Field

\begin{tabular}{|c|c|c|c|c|c|c|c|c|}
\hline \multirow[b]{3}{*}{ Treatment } & \multicolumn{4}{|c|}{ Rearings } & \multicolumn{4}{|c|}{ Crossings } \\
\hline & \multicolumn{2}{|c|}{ Training } & \multicolumn{2}{|c|}{ Test } & \multicolumn{2}{|c|}{ Training } & \multicolumn{2}{|c|}{ Test } \\
\hline & $M$ & $S E$ & $M$ & $S E$ & $M$ & $S E$ & $M$ & $S E$ \\
\hline Veh & 45.1 & 2.2 & 40.1 & 3. & 87.3 & 5.7 & 88.3 & 7.3 \\
\hline 2,5-HD & 45.0 & 2.1 & 39.2 & 2.2 & 89.6 & 4.3 & 93.0 & 4.6 \\
\hline
\end{tabular}

Note-Values are expressed as means and standard errors for 18 to 19 rats per experimental group. $F$ tests for simple effects of session revealed a significant reduction for all groups in rearing responses in the test session vis-d-vis the training session $(p<.05)$.

Table 5

Effects of Treatment With 2,5-Hexanedione $(20 \mathrm{mg} / \mathrm{kg}$ ) for 40 Days on Step-Down Latency (in Seconds) in the Inhibitory Avoidance Task

\begin{tabular}{cccccc}
\hline & \multicolumn{2}{c}{ Training } & & \multicolumn{2}{c}{ Test } \\
\cline { 2 - 3 } \cline { 5 - 5 } Treatment & $M$ & $S E$ & & $M$ & $S E$ \\
\hline Vehicle & 16.4 & 2.6 & & 252.7 & 28.7 \\
$2,5-H D$ & 13.3 & 1.7 & & 202.6 & 37.9 \\
\hline
\end{tabular}

Note-Values are expressed as means and standard errors for 18 to 19 rats per experimental group. $F$ tests for simple effects of sessions revealed a significant increase for all groups in step-down latency in the test session vis-a-vis the training session $(p<.0005$ for both vehicle and 2,5-HD groups). 
Table 6

Effects of Treatment With 2,5-Hexanedione $(20 \mathrm{mg} / \mathrm{kg})$ for 50 Days on the Number of Avoidance Responses and Intertrial Crossings in the Shuttle-Avoidance Task

\begin{tabular}{|c|c|c|c|c|c|c|c|c|}
\hline \multirow[b]{3}{*}{ Treatment } & \multicolumn{4}{|c|}{ Avoidance Responses } & \multicolumn{4}{|c|}{ Intertrial Crossings } \\
\hline & \multicolumn{2}{|c|}{ Training } & \multicolumn{2}{|c|}{ Test } & \multicolumn{2}{|c|}{ Training } & \multicolumn{2}{|c|}{ Test } \\
\hline & $M$ & $S E$ & $M$ & $S E$ & $M$ & $S E$ & $M$ & $S E$ \\
\hline Vehicle & 8.9 & 1.1 & 12.5 & 1.7 & 6.3 & 0.8 & 5.2 & 1.3 \\
\hline 2,5-HD & 9.3 & 1.3 & 13.4 & 1.3 & 5.7 & 1.3 & 8.9 & 1.4 \\
\hline
\end{tabular}

Note-Values are expressed as means and standard errors for 12 to 16 rats per experimental group. $F$ tests for simple effects of sessions revealed a significant increase for all groups in the number of rearings in the test session vis-â-vis the training session $(p<.01$ for both vehicle and 2,5 HD groups).

Step-down inhibitory performance was not affected by 2,5-HD, rats treated for 20 or 40 days showed retention scores (test-training difference) similar to those observed in control rats. This result indicates that memory of the task is not affected by chronic treatment with 2,5-HD. Step-down latency in the training session was not affected by the drug despite its depressant effect on motor performance in the open field.

Shuttle-avoidance performance was markedly impaired by treatment with $200 \mathrm{mg} / \mathrm{kg}$ of 2,5-HD. The number of shuttle-avoidance responses of treated rats was reduced to about $50 \%$ of that of control animals at 25 days and to about $30 \%$ at 50 days of treatment. Furthermore, in contrast to the performance of control animals, treated rats did not significantly increase the number of shuttle responses in the test session vis-à-vis the training session.

Various studies have reported that 2,5-HD produces sensory deficits (Abou-Donia et al., 1985; Bastone et al., 1987; DiVicenzo et al., 1976; Fedtke \& Bolt, 1987; Herskowitz et al., 1971; Misumi et al., 1985). Accordingly, animals treated with high doses of 2,5-HD should have been less sensitive to footshock than the animals in the vehicle group. However, in the step-down inhibitory avoidance task, the high-dose group appeared to be sensitive to footshock since the scores of these rats were similar to those observed in the vehicle rats. If the 2,5-HDtreated rats were hyporeactive to footshock, they might have been expected to present an impairment on retention of this task. Moreover, rats that have been treated chronically with $200 \mathrm{mg} / \mathrm{kg}$ of 2,5- $\mathrm{HD}$ (as in the present study) have not shown any change in nociception in the tail-flick apparatus (Pereira \& Izquierdo, unpublished results), whereas when injected acutely, the compound induced antinociception that was dose- and time-dependent (Pereira, Huang, \& Izquierdo, 1991).

The results obtained in the present shuttle-avoidance task would indicate that 2,5-HD-treated rats present a deficit in their memory of the task; however, the enormous involvement of motor function, as judged by the reduction of intertrial crossings (as well as in open-field performance at 15 and 30 days of treatment), preclude a conclusion about an effect on memory of this task. On the other hand, high-dose treated rats presented a lower number of shuttle responses in the training session than did the vehicle group, and it is possible that these animals have a deficit in learning rather than a deficit in memory; that is, they did not acquire the task and consequently did not exhibit a memory of the task. This issue could be assessed by analyzing the shuttle-avoidance behavior of treated rats during and after a period of recovery from intoxication. If the rats learned the association between CS (tone) and US (shock), their performance should have been superior to that of naive rats when the motor deficit was overcome by a period of recovery. This seems plausible because the establishment of a CS-US association consists of an early fundamental phase in learning the shuttle avoidance task, leading to instrumental conditioning (Izquierdo \& Cavalheiro, 1976a, 1976b).

The lower dose of 2,5-HD did not affect parameters examined in this study; thus, it seems that this dose is without toxic effects on the behavioral paradigms assessed.

In summary, the results of the present study demonstrate that chronic treatment with $200 \mathrm{mg} / \mathrm{kg}$ of $2,5-\mathrm{HD}$ causes a reduction in exploratory activity in the open field but does not impair habituation. Performance on stepdown inhibitory avoidance was not influenced by $2,5-\mathrm{HD}$, indicating that the treatment did not affect retention (memory) of this task. In contrast, performance on shuttle avoidance was greatly affected, and the treated rats exhibited no retention. Whether the memory deficits found in 2,5-HD-treated rats were a consequence of deficits in cognition of a relatively complex task or of motor dysfunctions remains to be determined.

\section{REFERENCES}

Abou-Donia, M. B., Makkawy, H. M., Campgell, G. M. (1985) Pattern of neurotoxicity of n-hexane, methyl n-butyl ketone, 2,5hexanediol, and 2,5-hexanedione alone and in combination with oethyl o-4-nitrophenyl phenylphosphonothioate in hens. Joumal of Toxicology \& Environmental Health, 16, 85-100.

Anthony, D. C., Boekelheide, K., Graham, D. G. (1983). The effect of 3,4-dimethyl substitution on the neurotoxicity of 2,5 hexanedione. Toxicology \& Applied Pharmacology, 71, 362-371.

Bastone, A., Frontal, N., Mallozzi, C., Seraccia, M., a SetTINI, L. (1987). Cholinesterase in blood plasma and tissues of rats treated with n-hexane or with its neurotoxic metabolite 2,5-hexanedione. Archives of Toxicology, 61, 138-144.

BraendgaARd, H., Sidenius, P. (1986). The retrograde fast component of axonal transport in motor and sensory nerves of the rat during administration of 2,5-hexanedione. Brain Research, 378, 1-7.

CourJ, D. , a MILKs, M. (1982). Toxicity and metabolism of the neurotoxic hexacarbons $n$-hexane, 2-hexanone and 2,5-hexanedione. Annual Review of Pharmacology \& Toxicology, 22, 145-166.

DeCAPruo, A. P., O'Neill, E. A. (1985). Alterations in rat axonal cytoskeletal proteins induced by in vitro and in vivo 2,5-hexanedione. Toxicology \& Applied Pharmacology, 78, 235-247.

DiVicenzo, G. D., Kaplan, C. J., a Dedinas, J. (1976). Characterization of the metabolism of methyl n-butyl ketone, methyl iso-butyl ketone and methyl ethyl ketone in guinea pig serum and their clearance. Toxicology \& Applied Pharmacology, 36, 511-522.

FeDtKe, N., Bolt, H. M. (1987). The relevance of 4,5-dihydroxy2-hexanone in the excretion kinetics of $n$-hexane metabolites. Archives of Toxicology, 61, 131-137.

Gerber, G. J., O'Shaughnessy, D. (1986). Comparison of the be- 
havioral effects of neurotoxic and systemically toxic agents: How discriminatory are behavioral tests of neurotoxicity? Neurobehavioral Toxicology \& Teratology, 8, 703-710.

HerskowttZ, A., IsHI, N., \& SCHAUMBURG, H. (1971). n-Hexane neuropathy: A syndrome occurrent as a result of industrial exposure. New England Joumal of Medicine, 285, 82-85.

Izquierdo, I., Cavalheiro, E. (1976a). The influence of stimulus pairing and of the shuttle-shock contingency on the performance of shuttle responses to a buzzer by weanling rats. Behavioral Biology, 17, 119-122.

Izquierdo, I., a Cavalheiro, E. (1976b). Three main factors in rat shuttle behavior: Their pharmacology and sequential entry in operation during a two-way avoidance session. Psychopharmacology, 49, 145-157.

LADEFOGED, O., Hass, U., Simonsen, L. (1989). Neurophysiological and behavioral effects of combined exposure to 2,5-hexanedione and acetone or ethanol in rats. Pharmacology \& Toxicology, 65, 372-375.

Misumi, J., Nagano, M., KaisaKu, J., \& Hrtoshi, T. (1985). Effects of vitamin B12 and B6 on 2,5-hexanedione-induced neuropathy. $\mathrm{Ar}$ chives of Toxicology, 56, 204-206.

Pereira, M. E., Dalmaz, C., Rosat, R., \& Izquierdo, I. (1988). Diazepam blocks the interfering effect of post-training behavioral manipulations on retention of a shuttle avoidance task. Psychopharmacology, 94, 402-404

Pereira, M. E., Huang, C. I., Izquierdo, I. (1991). Effect of acute administration of 2,5-hexanedione on nociception in rats. Brazilian Journal of Medical \& Biological Research, 24, 1025-1029.

Pereira, M. E., Medina, J. H., \& Izquierdo, I. (1989). Effect of pretraining flumazenil administration on the acquisition of three different tasks in rats. Brazilian Journal of Medical \& Biological Research, 22, 1501-1505.

Pereira, M. E., Rosat, R., Huang, C. H., Godoy, M. G. C., \& IzQUIERDO, 1. (1989). Inhibition by diazepam of the effect of additional training and of extinction on the retention of shuttle avoidance behavior in rats. Behavioral Neuroscience, 51, 108-113.

Rossi, A., Simonati, A., Rizzuto, N., \& Toschi, G. (1982). Neurotoxic action of 2,5-hexanedione on the autonomic nervous system Ultrastructural and functional alterations in the rat sympathetic superior cervical ganglion. Brain Research, 243, 373-377.

SPencer, P. S., Schaumburg, H. H., Sabri, M. I., \& Veronesi, B. (1980). The enlarging view of hexacarbon neurotoxicity. Critical Reviews in Toxicology, 7, 279-356.

(Manuscript received March 22, 1991; revision accepted for publication October $29,1991$. 